\title{
The quantification and assessment of depression and anxiety in patients with postoperative gastroparesis syndrome
}

This article was published in the following Dove Press journal:

Therapeutics and Clinical Risk Management

\author{
Li-juan Zheng' \\ Jia-chi $\mathrm{Ma}^{2}$ \\ Dong Fang ${ }^{3}$ \\ Li-gang $\mathrm{Wu}^{4}$ \\ Zhen-qiang Gong ${ }^{4}$ \\ Jian-bo $\mathrm{Qi}^{5}$ \\ Xiao-dan Zhao ${ }^{4}$ \\ Jian-bo $\mathrm{Du}^{4}$ \\ Pei-lan $\mathrm{Ma}^{5}$ \\ 'Department of Gastroenterology, \\ Gansu Province People's Hospital, \\ Lanzhou, People's Republic of China; \\ ${ }^{2}$ Department of General Surgery, \\ Gansu Province People's Hospital, \\ Lanzhou, People's Republic of China; \\ ${ }^{3}$ Department of Vascular Surgery, \\ Gansu Province People's Hospital, \\ Lanzhou, People's Republic of China; \\ ${ }^{4}$ Ningxia Medical University, Yinchuan, \\ Ningxia, People's Republic of China; \\ ${ }^{5}$ Gansu University of Traditional \\ Chinese Medicine, Lanzhou, \\ People's Republic of China
}

Correspondence: Jia-chi Ma

Department of General Surgery,

Gansu Provincial Hospital, Dong Gang

West Road 204, Cheng Guan Ward,

Lanzhou 730000, Gansu Province,

People's Republic of China

Tel +869318266691

Fax +86931 8266957

Email tsmjc@hotmail.com
Background: This study aimed to analyze the stage-situation depression and anxiety as well as independent influential factors in patients with postsurgical gastroparesis syndrome (PGS) and to provide dependent indications for treatment.

Patients and methods: The self-rating depression scale (SDS) and self-rating anxiety scale (SAS) were used to test the depression and anxiety of 53 patients with PGS, who were treated in the Department of Gastroenterological Surgery of Gansu Provincial Hospital from January 2012 to October 2016. A comparison between the SDS or SAS scores of patients with PGS and without PGS was undertaken; then, we retrospectively analyzed the factors influencing depression and anxiety in PGS patients.

Results: The patients with PGS' mean scores of depression and anxiety were $49.92 \pm 11.37$ and $50.91 \pm 6.57$, respectively, which were higher than that of patients without PGS in the Chinese population $(P<0.05)$. The results of multivariate logistic regression analysis indicated that the independent influential factors of depression and anxiety in patients with PGS included course of disease, pancreatic juice leakage, preoperative outflow tract obstruction, postoperative abdominal infection, and anastomotic complication $(P<0.05)$. Patients with a disease course longer than 30 days; with pancreatic juice leakage; and who suffered from preoperative outflow tract obstruction, postoperative abdominal infection, and anastomotic complication had higher ratios of depression and anxiety.

Conclusion: Depression and anxiety are clearly evident in patients with PGS, and we should pay attention to this phenomenon and provide appropriate treatment.

Keywords: postoperative gastroparesis syndrome, depression, anxiety, influential factors

\section{Background}

Postsurgical gastroparesis syndrome (PGS), also called functional gastric emptying disorder, often occurs following upper abdominal surgery, with an incidence rate of $2 \%-3 \%$. As verified by studies, the occurrence of PGS is associated with mentalnervous factors, surgery, and complications. ${ }^{1}$

PGS is often caused by upper abdominal surgery, especially gastric or pancreatic resection, and sometimes lower abdominal surgery, such as gynecological or obstetrical procedures. ${ }^{2,3}$ Its symptoms can be long lasting and often fail to be alleviated by usual medical therapy. Gastric reoperations usually prove useless. Its incidence rate has been increasing in recent years. PGS after gastrectomy has an incidence of approximately $0.4 \%$ to $5.0 \%$. Recently, nearly $2 \%$ to $3 \%$ of patients who have undergone abdominal operations suffer from PGS, which accounts for $19 \%$ of the entire PGS incidence..$^{2,45}$ PGS appears to be caused by multiple factors and mechanisms, with nervous system 
and gastrointestinal motility disorders considered the main causes. It is associated with a variety of symptoms, including injuries to arteries and veins, energy stagnancy and blood stasis in surgery, early satiety, postprandial fullness, nausea, vomiting, and abdominal pain. ${ }^{6}$ Frequency of complications varies directly according to the type and number of gastric operations. PGS after gastric surgery can also be due to muscular, neural, or humoral abnormalities. Delayed gastric emptying represents the inability to return to a standard diet by the end of the postoperative period. ${ }^{7}$ These symptoms prolong the enteral nutrition and parenteral nutrition course of the patients, which not only compounds the suffering of patients but also increases the risk of nosocomial infections. Gastric motility stimulant medication is commonly used. However, a large number of patients find it difficult to tolerate long-term treatment due to side effects, leading to drug-refractory symptoms, large economic burden, and extreme physical pain. Therefore, analysis of the incidence and risk factors for PGS is a crucial breakthrough to enhance recovery after surgery.

Depression, or major depressive disorder, is currently the fourth most common medical condition worldwide and is estimated to be the second most common disease by the year $2020 .{ }^{8}$ Currently, $50 \%$ to $60 \%$ of all antidepressant prescriptions are written by primary care physicians, ${ }^{9}$ indicating that the majority of patients seek treatment from primary care clinics. Effective treatment of depression is critical, as depression has an adverse impact on morbidity and mortality of several medical conditions, including coronary artery disease, diabetes, and cancer, often resulting in noncompliance with therapy for these disorders. ${ }^{10}$ Among various malignant diseases, pancreatic cancer is believed to have one of the highest rates of concomitant depressive disorders. ${ }^{11,12}$ Anxiety and depression have been reported to be the two most common psychological problems in cancer patients. ${ }^{13}$ Clinical research has shown that depression and anxiety are of major importance, resulting in more severe symptoms, impairment, subjective distress, and a long-term course of either anxiety or depression alone. ${ }^{14}$ Recently, many studies have shown that depression and anxiety affect the prognosis and long-term survival of cancer patients, ie, tumor stage and treatment methods in gastric cancer patients were significantly associated with depression. ${ }^{15}$ Psychological intervention is very critical for cancer patients, especially advanced cancer patients. ${ }^{16,17}$

A good psychological state plays as an important role in the diagnosis and treatment of cancer as a psychosomatic disease. Anxiety and depression have been reported to be the two most common psychological problems in cancer patients. Depression and anxiety have many effects on cancer patients, including reduced quality of life, altered decision making regarding treatment, increased desire for death, and a greater risk of suicide. The enteric nervous system plays a key role in emotions, earning it the nickname of "the second brain". Recent studies also have confirmed that the onset of PGS is closely related to neuropsychological factors, surgery, and complications. ${ }^{18}$ However, little research has been done regarding the factors influencing depression and anxiety in PGS patients. ${ }^{19,20}$ Currently, there is little research investigating the specific degree of and the influential factors of depression and anxiety of PGS patients.

The aim of this study was to use the self-rating depression scale (SDS) and self-rating anxiety scale (SAS) to examine the level of depression and anxiety in PGS patients and also to explore influential factors and provide recommendations for the comprehensive treatment of PGS.

\section{Ethics statement}

This study was approved by the Medical Ethical Committee of the Gansu Cancer Center (sykj0065), Gansu Provincial Hospital. Written informed consent was obtained from all participants.

\section{Patients and Methods}

\section{Patients}

The observation group consisted of patients with PGS (28 males and 25 females) who underwent radical surgery for gastric or pancreatic cancer in Gansu Provincial Hospital of General Surgery between January 2011 and October 2016. All patients in this study met the PGS diagnostic criteria: ${ }^{3}$ 1) frequent nausea, vomiting, or stomach retention after abdominal surgery and has been qualified without outflow tracked by gastroscopy or upper gastrointestinal tract examination; 2) drainage fluid from stomach was over 600 to $800 \mathrm{~mL}$ per day for at least 6-10 days; 3) no serious water, electrolyte, or acid-base imbalance; 4) no primary disease that could cause PGS, such as thyroid hypofunction; and 5) no medication history of drugs such as morphine that could affect stomach smooth muscle contraction. In the same period, 60 patients without PGS who underwent radical surgery for gastric and pancreatic cancer were randomly selected as a control group. In order to complete this questionnaire, patients also had to fulfill the following conditions: junior high school education or higher, no brain disease that affected their cognition, no major psychological impairments, and sufficient comprehension. 


\section{Clinical data collection}

Questionnaires, SDS, and SAS were administered to patients on the 7th day after the diagnosis of PGS was confirmed in hospital. This study used a double-blind trial conducted by professionally trained doctors and nurses. The questionnaires were filled out by patients with at least one of three trained staff members or the physician present. The patients completed the questionnaires independently and without families present, with doctors available to clarify questions as needed regarding the 20 items of the SDS and the 20 items of the SAS. A raw score $(\mathrm{X})$ was obtained by adding all the scores corresponding to the 20 items, and then it was converted through the formula: $Y=\operatorname{Int}(1.25 \mathrm{X})$, namely, dividing the raw score by 1.25 , the integer was taken as the standard score (Y), and a standard score $\geq 50$ points meant the presence of anxiety or depression. A comparative analysis was made between the final data and the control group SDS and SAS.

\section{Statistical analysis}

A database was established using Excel. Data were presented as mean \pm SD. Statistic comparisons were performed using the Student's $t$-test for paired observations or by chi-square test for grouped comparison. Logistic regression was used for analysis of the correlated influence factors. We used the SAS 11.0 software to analyze the data. Statistical significance level was set at $P<0.05$.

\section{Results}

\section{Results of depression and anxiety evaluation}

The comparison between the SDS and SAS scores of PGS patients and patients without PGS (control group) showed that the PGS patients had higher SDS and SAS scores than patients without PGS, showing statistically significant differences (SDS: [49.92 \pm 11.37$]$ points vs [43.07 \pm 6.02$]$ points, $P<0.01$; SAS: [50.91 \pm 6.51$]$ points vs [40.35 \pm 9.31$]$ points, $P<0.01$ ), as shown in Table 1 . According to Chinese norms, 50 points was a critical value, and a standard score of not less than 50 points indicated no presence of anxiety

Table I Mean scale value of PGS patients compared to patients without PGS (mean \pm standard deviation)

\begin{tabular}{lllll}
\hline Scale & $\begin{array}{l}\text { Patients } \\
\text { with PGS }\end{array}$ & $\begin{array}{l}\text { Patients } \\
\text { without PGS }\end{array}$ & t-value & P-value \\
\hline SDS & $49.83 \pm 11.37$ & $43.07 \pm 6.02$ & 6.925 & $<0.01$ \\
SAS & $50.91 \pm 6.51$ & $38.35 \pm 9.31$ & 7.190 & $<0.01$ \\
\hline
\end{tabular}

Abbreviations: PGS, postsurgical gastroparesis syndrome; SDS, self-rating depression scale; SAS, self-rating anxiety scale. or depression. In the observation group, 31 patients had a depression standard score of more than 50 points, the depression incidence was $58.5 \%$ (31/53), and 35 patients had an anxiety standard score of not less than 50 points, the anxiety incidence was $66.0 \%(35 / 53)$. In the control group, the incidence of depression and anxiety was $18.3 \%(11 / 60)$ and $23.3 \%(14 / 60)$, respectively. The incidence of depression and anxiety in the observation group was significantly higher than that in the control group $(P<0.01)$. This result indicated that the patients in the observation group had obvious depression and anxiety symptoms.

\section{Single-factor analysis of relationship of anxiety-depression and clinical characteristics}

The results of single-factor analysis showed that the depression of 53 PGS patients was associated with the disease course, postoperative pancreatic juice leakage, preoperative gastrointestinal outflow tract obstruction, and postoperative anastomotic stoma complications. Patients with the following had a relatively high incidence rate of depression $(P<0.05)$ : a disease course of more than 30 days, postoperative occurrence of pancreatic leakage, preoperative gastrointestinal outflow tract obstruction, and postoperative anastomotic stoma complications. The occurrence of anxiety in PGS patients in this group was significantly correlated with a disease course of more than 30 days, postoperative abdominal infection, postoperative pancreatic leakage, preoperative gastrointestinal outflow tract obstruction, and postoperative anastomotic stoma complications $(P<0.05)$. Patients' depression and anxiety were not associated with sex, age, surgery duration, and perioperative hypoproteinemia $(P>0.05$, Tables 2 and 4).

\section{Multi-factor analysis of relationship of anxiety-depression and clinical characteristics}

The results of logistic multi-factor analysis showed a disease course of more than 30 days, postoperative pancreatic leakage, preoperative gastrointestinal outflow tract obstruction, and postoperative anastomotic stoma complications were influential factors in depression in PGS patients $(P<0.05)$. A disease course of more than 30 days, postoperative abdominal infection, postoperative pancreatic juice leakage, preoperative gastrointestinal outflow tract obstruction, and postoperative anastomotic stoma complications were significantly correlated with the presence of intraperitoneal infection $(P<0.05$; Tables 3 and 5). 
Table 2 Comparison of clinical features in PGS patients with and without depression

\begin{tabular}{|c|c|c|c|}
\hline $\begin{array}{l}\text { Clinical } \\
\text { characteristics }\end{array}$ & Cases (n) & $\begin{array}{l}\text { Standard } \\
\text { scale }>50\end{array}$ & $P$-value \\
\hline \multicolumn{3}{|l|}{ Sex } & \multirow[t]{3}{*}{0.530} \\
\hline Male & 28 & 18 & \\
\hline Female & 25 & 13 & \\
\hline \multicolumn{3}{|l|}{ Age (years) } & \multirow[t]{3}{*}{0.338} \\
\hline$\leq 60$ & 18 & 10 & \\
\hline$>60$ & 35 & 21 & \\
\hline \multicolumn{3}{|c|}{ Disease course (days) } & \multirow[t]{3}{*}{$0.040 *$} \\
\hline$\leq 30$ & 39 & 20 & \\
\hline$>30$ & 14 & 11 & \\
\hline \multicolumn{3}{|c|}{ Postoperative fasting blood glucose (mmol/L) } & \multirow[t]{3}{*}{0.253} \\
\hline$\leq 8$ & 41 & 26 & \\
\hline$>8$ & 12 & 5 & \\
\hline \multicolumn{3}{|c|}{ Postoperative abdominal infection } & \multirow[t]{3}{*}{0.271} \\
\hline With & 8 & 5 & \\
\hline Without & 45 & 26 & \\
\hline \multicolumn{3}{|c|}{ Postoperative analgesia pump } & \multirow[t]{3}{*}{0.114} \\
\hline With & 39 & 22 & \\
\hline Without & 14 & 9 & \\
\hline \multicolumn{3}{|c|}{ Perioperative hypoalbuminemia } & \multirow[t]{3}{*}{0.362} \\
\hline With & 12 & 7 & \\
\hline Without & 31 & 24 & \\
\hline \multicolumn{3}{|c|}{ Intraoperative blood loss (mL) } & \multirow[t]{3}{*}{0.211} \\
\hline$\leq 500$ & 30 & 22 & \\
\hline$>500$ & 23 & 27 & \\
\hline \multicolumn{3}{|c|}{ Operative time (hours) } & \multirow[t]{3}{*}{0.173} \\
\hline$\leq 3.0$ & 27 & 17 & \\
\hline$>3.0$ & 24 & 14 & \\
\hline \multicolumn{3}{|c|}{ Pancreatic juice leakage } & \multirow[t]{3}{*}{0.040} \\
\hline With & 6 & 5 & \\
\hline Without & 47 & 26 & \\
\hline \multicolumn{3}{|c|}{ Preoperative gastrointestinal outflow tract obstruction } & \multirow[t]{3}{*}{$0.00 I^{*}$} \\
\hline With & 15 & 14 & \\
\hline Without & 38 & 17 & \\
\hline \multicolumn{3}{|c|}{ Postoperative anastomotic stoma complications } & \multirow[t]{3}{*}{$0.013^{*}$} \\
\hline With & 12 & II & \\
\hline Without & 41 & 20 & \\
\hline
\end{tabular}

Note: *The difference was statistically significant $(P<0.05)$.

Abbreviation: PGS, postsurgical gastroparesis syndrome.

\section{Discussion}

PGS is one of the most common complications following gastric and pancreatic surgery, and approximately $40 \%$ of PGS patients have mental illness symptoms of varying degrees. ${ }^{5,6}$

Table 3 Logistic regression analysis of PGS patients with depression

\begin{tabular}{llll}
\hline Variables & OR value & $\mathbf{9 5 \%} \mathbf{C l}$ & P-value \\
\hline Course of disease $>30$ days & $\mathrm{I} .78 \mathrm{I}$ & $\mathrm{I} .5 \mathrm{I} 2-2.203$ & 0.013 \\
Pancreatic juice leakage & $\mathrm{I} .726$ & $\mathrm{I} .362-1.972$ & 0.000 \\
$\begin{array}{l}\text { Preoperative outflow tract } \\
\text { obstruction }\end{array}$ & $\mathrm{I} .409$ & $\mathrm{I} .27 \mathrm{I}-\mathrm{I} .836$ & 0.002 \\
$\begin{array}{l}\text { Anastomotic stoma } \\
\text { complications }\end{array}$ & $\mathrm{I} .463$ & $\mathrm{I} .263-\mathrm{I} .782$ & $0.00 \mathrm{I}$ \\
\hline
\end{tabular}

Abbreviation: PGS, postsurgical gastroparesis syndrome.
Table 4 Comparison of clinical features in PGS patients with and without anxiety

\begin{tabular}{|c|c|c|c|}
\hline $\begin{array}{l}\text { Clinical } \\
\text { characteris }\end{array}$ & Cases (n) & $\begin{array}{l}\text { Standard } \\
\text { scale }>\mathbf{5 0}\end{array}$ & P-value \\
\hline \multicolumn{3}{|l|}{ Sex } & 0.19 \\
\hline Male & 28 & 19 & \\
\hline Female & 25 & 16 & \\
\hline \multicolumn{3}{|l|}{ Age (years) } & 0.45 \\
\hline$\leq 60$ & 18 & II & \\
\hline$>60$ & 35 & 24 & \\
\hline \multicolumn{3}{|c|}{ Disease course (days) } & $0.002 *$ \\
\hline$\leq 30$ & 39 & 26 & \\
\hline$>30$ & 14 & 9 & \\
\hline \multicolumn{3}{|c|}{ Postoperative fasting blood glucose (mmol/L) } & 0.728 \\
\hline$\leq 8$ & 41 & 28 & \\
\hline$>8$ & 12 & 7 & \\
\hline \multicolumn{3}{|c|}{ Postoperative abdominal infection } & 0.027 \\
\hline With & 9 & 8 & \\
\hline Without & 45 & 27 & \\
\hline \multicolumn{3}{|c|}{ Postoperative analgesia pump } & 0.427 \\
\hline With & 39 & 25 & \\
\hline Without & 14 & 10 & \\
\hline \multicolumn{3}{|c|}{ Perioperative hypoalbuminemia } & 0.719 \\
\hline With & 12 & 6 & \\
\hline Without & 31 & 29 & \\
\hline \multicolumn{3}{|c|}{ Intraoperative blood loss (mL) } & 0.282 \\
\hline$\leq 500$ & 30 & 21 & \\
\hline$>500$ & 23 & 14 & \\
\hline \multicolumn{3}{|c|}{ Operative time (hours) } & 0.495 \\
\hline$\leq 3.5$ & 27 & 19 & \\
\hline$>3.50$ & 24 & 16 & \\
\hline \multicolumn{3}{|c|}{ Pancreatic juice leakage } & 0.026 \\
\hline With & 6 & 6 & \\
\hline Without & 47 & 29 & \\
\hline \multicolumn{3}{|c|}{ Preoperative gastrointestinal outflow tract obstruction } & $0.003 *$ \\
\hline With & 15 & 14 & \\
\hline Without & 38 & 21 & \\
\hline \multicolumn{3}{|c|}{ Postoperative anastomotic stoma complications } & $0.03 I^{*}$ \\
\hline With & 12 & II & \\
\hline Without & 41 & 24 & \\
\hline
\end{tabular}

Note: $*$ The difference was statistically significant $(P<0.05)$.

Abbreviation: PGS, postsurgical gastroparesis syndrome.

After clinical observation, the authors found that PGS patients have depression and anxiety symptoms of varying degrees, and their presence significantly impacts patients' treatment compliance and the recovery of gastric motility. Therefore, studying the psychological problems of PGS patients and

Table 5 Logistic regression analysis of PGS patients with anxiety

\begin{tabular}{llll}
\hline Variables & OR value & $\mathbf{9 5 \%} \mathbf{C l}$ & $P$-value \\
\hline Course of disease $>30$ days & 1.864 & $1.653-2.291$ & 0.017 \\
Postoperative abdominal infection & 1.726 & $1.309-1.957$ & 0.000 \\
$\begin{array}{l}\text { Preoperative outflow tract } \\
\text { obstruction }\end{array}$ & 1.472 & $1.203-1.852$ & 0.001 \\
$\begin{array}{l}\text { Pancreatic juice leakage } \\
\text { Anastomotic stoma complications }\end{array}$ & 1.863 & $1.735-2.170$ & 0.000 \\
\end{tabular}

Abbreviation: PGS, postsurgical gastroparesis syndrome. 
their influential factors, as well as multi-disciplinary, comprehensive treatment for the influential factors, are of vital significance to clinical practice.

Scale of measure is one of the important examinations in modern medicine. It is characterized by a relatively wide application in clinical treatment and scientific research with high validity, good reliability, and simple and easy application, and its contents involve emotional experience and emotion-related somatic symptoms. ${ }^{21}$ The application in gastrointestinal surgery not only facilitates the patient's diagnosis and treatment but also plays an active role in helping medical staff to adapt the traditional treatment and nursing modes. ${ }^{22}$ SAS and SDS are characterized by a relatively wide application in clinical treatment and scientific research with high validity, good reliability, and simple and easy application, and its contents involve emotional experience and emotion-related somatic symptoms, and these symptoms are relatively common in PGS patients. Measurement, using the scale, found that most PGS patients presented with depression and anxiety symptoms at 7-45 days after radical surgery for gastric or pancreatic cancer, and most of the patients showed personality deviation, such as stubbornness and stereotypy, irritability, disinclination to move and talk, susceptibility and suspiciousness, which lasted for a long period of time. In order to accurately and comprehensively study the adverse emotions of a patient, the authors of this study carried out the measurements at day 7 after the diagnosis of PGS was confirmed by a clinical doctor. The investigation results indicated that PGS patients had significantly higher SAS and SDS scores (49.83 \pm 11.37 and 50.91 \pm 6.51 points, respectively) than patients without

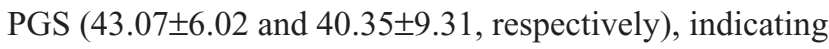
that PGS patients had a higher depression and anxiety score than the normal population and showing the presence of anxiety or depression. The results of logistic multi-factor regression analysis found that a disease course of more than 30 days, postoperative occurrence of pancreatic leakage, preoperative gastrointestinal outflow tract obstruction, and postoperative anastomotic stoma complications were independent influential factors for depression and anxiety in PGS patients. These results indicated that the medical history of PGS patients should be studied comprehensively and carefully during clinical practice. As for patients with a disease course of more than 30 days, postoperative abdominal infection, postoperative occurrence of pancreatic juice leakage, preoperative gastrointestinal outflow tract obstruction, and postoperative anastomotic stoma complications, the observations of the patient's psychological status should be consolidated and the patient's abnormal psychological status and behaviors should be detected early during the active treatment of PGS, so that effective psychological intervention can be carried out and the patient's psychological status can be corrected. The authors' department provided psychological intervention to patients with depression and anxiety through the timely application of cognitive psychological therapeutic principle, so that they could be guided to establish healthy thinking, emotional, and behavioral psychology. Out of the 53 patients with PGS in this study, comprehensive conservative treatment and psychological counseling were successful in 51 patients; two patients had no response to conservative treatment, then underwent another surgery for gastrostomy for the placement of intranasal jejunum nutrient canal, and became convalescent 5 weeks thereafter. The authors proposed the following suggestions with reference to the treatment methods for depression and anxiety, among other mental diseases, after the psychological intervention treatment methods for functional gastrointestinal diseases were taken into consideration: 1) cognitive behavior therapy, dynamic psychological therapy, biological feedback therapy, and relaxation therapy, etc. can be adopted for psychological intervention so that patients can establish healthy thinking and emotional and behavioral psychology. Doctorpatient communication should be consolidated to stimulate patients' psychosomatic self-regulation so that the treatment of primary diseases can be greatly boosted on the basis of the elimination of depression and anxiety. ${ }^{13,23-25}$ 2) Drug treatment: the current psychotropic antidepressant and antianxiety drugs mainly include $\beta$-adrenaline receptor blocking agent, mono-oxygenase inhibitor, benzodiazepine, selective 5-hydroxytryptamine reuptake inhibitor, and other drugs (such as buspirone hydrochloride tablets and venlafaxine). ${ }^{26-28}$ Psychiatrists are advised to give individualized treatment after consultation under the condition of drug intervention. These results indicate that improvement in psychological status is beneficial to the recovery of patients' physiological functions. In this paper, because the treatment of depression and anxiety was undertaken by psychologists and psychiatrists, there are relatively little data on the specific treatment of depression and anxiety, and we will reinforce this in a later study.

\section{Conclusion}

Most PGS patients have obvious depression and anxiety emotions; a disease course of more than 30 days, postoperative occurrence of pancreatic leakage, preoperative gastrointestinal outflow tract obstruction, and postoperative anastomotic stoma complications are the independent risk factors; patients are advised to adopt psychological intervention and drug therapies during their treatment to promote fast recovery. 
Depression and anxiety are clearly evident in patients with PGS, and we should pay attention to this phenomenon and provide appropriate treatment.

\section{Acknowledgments}

This study was supported by the National Natural Science Foundation of China, no 81260325, and Hospital Research Foundation of Gansu Provincial People's Hospital, no 17GSSY1-4.

\section{Disclosure}

The authors report no conflicts of interest in this work.

\section{References}

1. Meng H, Zhou D, Jiang X, Ding W, Lu L. Incidence and risk factors for postsurgical gastroparesis syndrome after laparoscopic and open radical gastrectomy. World J Surg Oncol. 2013;11:144.

2. Dong K, Yu XJ, Li B, Wen EG, Xiong W, Guan QL. Advances in mechanisms of postsurgical gastroparesis syndrome and its diagnosis and treatment. Chin J Dig Dis. 2006;7(2):76-82.

3. Dong K, Li B, Guan QL, Huang T. Analysis of multiple factors of postsurgical gastroparesis syndrome after pancreaticoduodenectomy and cryotherapy for pancreatic cancer. World J Gastroenterol. 2004;10(16):2434-2438.

4. Cheong KB, Zhang JP, Huang Y. The effectiveness of acupuncture in postoperative gastroparesis syndrome - a systematic review and metaanalysis. Complement Ther Med. 2014;22(4):767-786.

5. Sun BM, Luo M, Wu SB, Chen XX, Wu MC. Acupuncture versus metoclopramide in treatment of postoperative gastroparesis syndrome in abdominal surgical patients: a randomized controlled trial. Zhong Xi Yi Jie He Xue Bao. 2010;8(7):641-644.

6. Parkman HP, Hasler WL, Fisher RS; American Gastroenterological Association. American Gastroenterological Association technical review on the diagnosis and treatment of gastroparesis. J Gastroenterology. 2004;127(5):1592-1622.

7. Wente MN, Bassi C, Dervenis C, et al. Delayed gastric emptying (DGE) after pancreatic surgery: a suggested definition by the International Study Group of Pancreatic Surgery (ISGPS). Surgery. 2007;142(5):761-768.

8. Murray CJ, Lopez AD. Alternative projections of mortality and disability by cause 1990-2020: Global Burden of Disease Study. Lancet. 1997; 349(9064):1498-1504.

9. Corey-Lisle PK, Nash R, Stang P, Swindle R. Response, partial response, and nonresponse in primary care treatment of depression. Arch Intern Med. 2004;164(11):1197-1204.

10. No authors listed. Managing depression in primary care: achieving remission. Prim Care Companion J Clin Psychiatry. 2006;8(2):88-97.

11. Massie MJ. Prevalence of depression in patients with cancer. $J$ Natl Cancer Inst Monogr. 2004;32:57-71.

Therapeutics and Clinical Risk Management

\section{Publish your work in this journal}

Therapeutics and Clinical Risk Management is an international, peerreviewed journal of clinical therapeutics and risk management, focusing on concise rapid reporting of clinical studies in all therapeutic areas, outcomes, safety, and programs for the effective, safe, and sustained use of medicines. This journal is indexed on PubMed Central, CAS,
12. Passik SD, Breitbart WS. Depression in patients with pancreatic carcinoma. Diagnostic and treatment issues. Cancer. 1996;78(3 Suppl): 615-626.

13. Takahashi T, Hondo M, Nishimura K, et al. Evaluation of quality of life and psychological response in cancer patients treated with radiotherapy. Radiat Med. 2008;26(7):396-401.

14. Angst J. Depression and anxiety: implications for nosology, course, and treatment. J Clin Psychiatry. 1997;58(Suppl 8):3-5.

15. Yu H, Wang Y, Ge X, Wu X, Mao X. Depression and survival in Chinese patients with gastric cancer: a prospective study. Asian Pac JCancer Prev. 2012;13(1):391-394.

16. Burgess C, Cornelius V, Love S, Graham J, Richards M, Ramirez A. Depression and anxiety in women with early breast cancer: five year observational cohort study. BMJ. 2005;330(7493):702.

17. Wilson KG, Chochinov HM, Skirko MG, et al. Depression and anxiety disorders in palliative cancer care. J Pain Symptom Manage. 2007;33(2): $118-129$.

18. Ledgerwood DM, Petry NM. Subtyping pathological gamblers based on impulsivity, depression, and anxiety. Psychol Addict Behav. 2010; 24(4):680-688.

19. Serbic D, Pincus T. Pain-related guilt in low back pain. Clin J Pain. 2014;30(12):1062-1069.

20. Song MH, Zhu GJ, Ma L, et al. Comparative analysis of bilirubin in correlation to albumin between nephrotic syndrome patients and postoperative gastroparesis syndrome patients. Genet Mol Res. 2014;13(4): 9403-9411.

21. Engel GL. The need for a new medical model: a challenge for biomedicine. Science. 1977;196(4286):129-136.

22. Hong JS, Tian J. Prevalence of anxiety and depression and their risk factors in Chinese cancer patients. Support Care Cancer. 2014;22(2): 453-459.

23. Kiecolt-Glaser JK, Robles TF, Heffner KL, Loving TJ, Glaser R. Psycho-oncology and cancer: psychoneuroimmunology and cancer. Ann Oncol. 2002;13(Suppl 4):165-169.

24. Parkman HP, Yates K, Hasler WL, et al. Cholecystectomy and clinical presentations of gastroparesis. Dig Dis Sci. 2013;58(4): 1062-1073.

25. Zhang CY. [Observation on therapeutic effect of routine acupoints plus mental activity-adjusting acupoints in the treatment of post-surgical gastroparesis syndrome]. Zhen Ci Yan Jiu. 2010;35(6):458-461. Chinese [with English abstract].

26. Zimmerman M, Martinez JH, Attiullah N, Friedman M, Toba C, Boerescu DA. The remission from depression questionnaire as an outcome measure in the treatment of depression. Depress Anxiety. 2014; 31(6):533-538.

27. Hartley S, Barrowclough C, Haddock G, et al. Anxiety and depression in psychosis: a systematic review of associations with positive psychotic symptoms. Acta Psychiatr Scand. 2013;128(5):327-346.

28. DeJean D, Giacomini M, Vanstone M, Brundisini F. Patient experiences of depression and anxiety with chronic disease: a systematic review and qualitative meta-synthesis. Ont Health Technol Assess Ser. 2013;13(16):1-33. eCollection 2013.

EMBase, Scopus and the Elsevier Bibliographic databases. The manuscript management system is completely online and includes a very quick and fair peer-review system, which is all easy to use. Visit http://www.dovepress.com/testimonials.php to read real quotes from published authors. 